\title{
Prevalence and risk factors of being overweight or obese among children and adolescents in northeast China
}

\author{
Xiaofan Guo', Liqiang Zheng ${ }^{2}$, Yang Li', Xiaoyu Zhang ${ }^{3}$, Shasha Yu' ${ }^{1}$, Hongmei Yang ${ }^{1}$, Xingang Zhang ${ }^{1}$, Zhaoqing Sun ${ }^{4}$ \\ and Yingxian Sun ${ }^{1}$
}

BACKGROUND: We determined the prevalence and risk profiles of being overweight or obese among children and adolescents in rural northeast China.

METHODS: We conducted a cross-sectional study consisting of 4,094 children and adolescents aged 5-18y. Anthropometric measurements and information on health-related variables were collected by well-trained personnel. Odds ratios (ORs) are presented with 95\% confidence intervals (Cls).

RESULTS: The overall prevalence of subjects who were overweight or obese was $21.8 \%$ (15.4\% overweight and 6.4\% obese). Among boys, getting more sleep was found to be a protective factor against being overweight or obese, and a higher monthly family income (2,000-5,000 Chinese yuan (CNY); 1 $C N Y=0.163$ US dollar) was associated with an increased risk as compared with lower incomes. For girls, not having breakfast every day conferred higher odds of being overweight or obese (OR, 1.45 (95\% confidence interval (Cl), 1.11-1.91)). When both parents were overweight, this increased the risk of a child being overweight or obese in both boy (overweight father: OR, 1.54 (95\% Cl, 1.26-1.89); overweight mother: OR, 1.73 (95\% Cl, 1.352.22)) and girl participants (overweight father: $\mathrm{OR}, 2.01(95 \% \mathrm{Cl}$, 1.57-2.57); overweight mother: OR, 1.45 (95\% Cl, 1.07-1.96)).

CONCLUSION: The prevalence of pediatric obesity in rural China was relatively high. Risk profiles should be fully considered when planning prevention and treatment programs for pediatric obesity.

$\mathbf{T}$ he prevalence of children and adolescents who are overweight or obese has increased dramatically and reached alarming levels in recent years, affecting both developed and developing countries. Given the adverse health consequences in young adults that are associated with being overweight or obese, such as metabolic disorders, type 2 diabetes, hypertension, sleep apnea, adulthood obesity, and higher rates of mortality in young adults (1-5), it has become a global public health problem that requires more attention worldwide.

This trend of rising prevalence has been observed in China. In the most developed metropolises, including Beijing and Shanghai, the prevalence of overweight or obese children increased twofold to threefold between 1985 and 1995. During 2005-2010, the increase rate of pediatric obesity was even higher in rural areas than that in urban areas $(6,7)$.

Although the genetic cause for obesity is not to be ignored, lifestyle behaviors and environmental factors are more likely to be closely related to the increased prevalence of overweight problems in the population. Several studies in China have suggested that lifestyle and sociodemographic factors such as watching too much TV, living in rural areas, and having overweight parents, increases the risk that children and adolescents will be overweight or obese (8-11). Because the management of bodily weight problems in this segment of the population is often based on lifestyle modifications, identification of the associated risk factors is a top priority.

The prevalence of childhood and adolescent obesity and associated factors has been reported in other studies conducted in China, but most of them were focused on urban areas; related information for rural areas is relatively limited. Likely because of an imbalance in economic development, the health resources in rural areas of northeast China are relatively poor as compared with those in the south, and the lack of health resources is often ignored by many health workers. In addition, data concerning dietary habits and anthropological measurement results among these children are lacking. Most important, the lifestyle habits and customs in northeast China are markedly different from those of other regions. For example, due to the cultural differences, most residents in northeast China tend to prefer a large quantity of food, whereas residents in south China focus more on the quality of food and eat less in everyday meals. Moreover, the different diet structures between the regions may also have different impacts on weight status. Therefore, we believe that the prevalence of overweight or obese people in the pediatric population, as well as the associated risk factors, might be quite different in northeast China and warrant investigation.

To reduce the prevalence of childhood and adolescent obesity and promote health in this segment of the population of rural northeast China, it is of key importance to establish strategies that are based on the specific risk factors of this locale.

\footnotetext{
Department of Cardiology, First Hospital of China Medical University, Shenyang, People's Republic of China; ${ }^{2}$ Department of Clinical Epidemiology, Library, Shengjing Hospital of China Medical University, Shenyang, People's Republic of China; ${ }^{3}$ Shenyang Eye Research Institute, Fourth People' Hospital, Shenyang, People's Republic of China; ${ }^{4}$ Department of Cardiology, Shengjing Hospital of China Medical University, Shenyang, People's Republic of China. Correspondence: Yingxian Sun (sunyingxian12@yahoo.com.cn) 
Therefore, in the current study, we determined the prevalence of overweight and obese young people in a large population sample in rural northeast China. We also investigated whether lifestyle behaviors, dietary habits, and parental body weight were associated with obesity in this population.

\section{RESULTS}

The population sample consisted of 2,131 boys and 1,963 girls, with a mean age of $10.9 \pm 2.7 \mathrm{y}$. The overall prevalences for being overweight or obese were 15.4 and $6.4 \%$, respectively. Of the 4,094 participants, 568 boys (26.7\%) and 326 girls (16.6\%) were found to be overweight or obese. The mean BMI of the boys was $19.19 \pm 3.93 \mathrm{~kg} / \mathrm{m}^{2}$ and that of the girls was $18.42 \pm 3.26 \mathrm{~kg} / \mathrm{m}^{2}$.

Table 1 presents baseline characteristics of participants by sex. Boys had higher BMI than girls $(19.19 \pm 3.93$ vs. $18.42 \pm 3.26 ; P<0.001)$. The prevalence of overweight and obesity for boys was higher as compared with girls. Girls had lower mean systolic blood pressure and higher paternal BMI as compared with boys.

Table 2 presents the prevalence of overweight and obesity among different groups by sex. The prevalence of overweight or obese participants was higher in the 5-8 y age groups in both the sexes. Children of overweight parents were more likely to be overweight or obese. Sleep duration and snack habit were significantly associated with the prevalence of overweight or obesity for boys and girls, respectively.

Table 1. Baseline characteristics of the participants by $\operatorname{sex}(N=4,094)$

\begin{tabular}{lccc}
\hline & Boys & Girls & $P$ value \\
\hline Age $(\mathrm{y})$ & $10.9 \pm 2.65$ & $10.97 \pm 2.69$ & 0.45 \\
5-8 $(n=899)$ & $7.37 \pm 0.66$ & $7.30 \pm 0.73$ & 0.18 \\
$9-11(n=1,439)$ & $9.97 \pm 0.81$ & $9.96 \pm 0.80$ & 0.71 \\
$12-14(n=1,347)$ & $13.03 \pm 0.80$ & $13.03 \pm 0.81$ & 0.92 \\
$\quad 15-18(n=409)$ & $15.35 \pm 0.60$ & $15.30 \pm 0.61$ & 0.38 \\
Han race & $82.9(1,767)$ & $81.5(1,599)$ & 0.22 \\
Weight $(\mathrm{kg})$ & $41.19 \pm 14.93$ & $38.82 \pm 12.2$ & $<0.001^{*}$ \\
Height $(\mathrm{cm})$ & $144.18 \pm 15.78$ & $143.18 \pm 14.03$ & $0.03^{*}$ \\
BMI $\left(\mathrm{kg} / \mathrm{m}^{2}\right)$ & $19.19 \pm 3.93$ & $18.42 \pm 3.26$ & $<0.001^{*}$ \\
Normal weight & $73.3(1,563)$ & $83.4(1,637)$ & $<0.001^{*}$ \\
Overweight & $17.4(370)$ & $13.3(261)$ & \\
Obese & $9.3(198)$ & $3.3(65)$ & \\
SBP $(\mathrm{mmHg})$ & $109.61 \pm 13.24$ & $107.89 \pm 13.33$ & $<0.001^{*}$ \\
DBP $(\mathrm{mmHg})$ & $66.62 \pm 9.92$ & $67.07 \pm 9.87$ & 0.15 \\
Sleep duration $(\mathrm{h})$ & $8.75 \pm 1.10$ & $8.71 \pm 1.18$ & 0.28 \\
Nonsmoking & $85.3(1818)$ & $86.4(1697)$ & 0.30 \\
No alcohol use & $82.5(1759)$ & $85.6(1680)$ & $0.01^{*}$ \\
Mother's BMI $\left(\mathrm{kg} / \mathrm{m}^{2}\right)$ & $22.41 \pm 2.97$ & $22.38 \pm 3.06$ & 0.75 \\
Father's BMl $\left(\mathrm{kg} / \mathrm{m}^{2}\right)$ & $23.88 \pm 3.23$ & $24.12 \pm 3.21$ & $0.02^{*}$ \\
\hline & & & \\
& & &
\end{tabular}

Data are expressed as $\%(n)$ or as the mean \pm SD. ${ }^{*} P<0.05$, statistically significant difference.

DBP, diastolic blood pressure; SBP, systolic blood pressure.
Table 3 presents the multivariable logistic regression analysis of risk factors related to overweight or obesity. Among boys, races other than Han Chinese were associated with a higher odds of being overweight or obese (odds ratio (OR): 1.36; 95\% confidence interval (CI): 1.06-1.75). Moreover, among boys, a longer sleep duration $(>9 \mathrm{~h})$ was associated with a lower odds of overweight or obesity (OR: 0.72; 95\% CI: 0.57-0.92). Boys with a monthly family income of 2,000-5,000 Chinese yuan (CNY; $1 \mathrm{CNY}=0.163$ US dollar) had an increased odds of being overweight or obese in comparison with boys with a lower family income. For girls, not having breakfast every day was related to higher odds of being overweight or obese (OR: 1.45; 95\% CI: 1.11-1.91). Having an overweight mother or overweight father was associated with increased odds of overweight or obesity for boys and girls (for boys, overweight father: OR, 1.54; 95\% CI: 1.26-1.89; overweight mother: OR, 1.73; 95\% CI: 1.35-2.22; for girls, overweight father: OR, 2.01; 95\% CI: 1.57-2.57; overweight mother: OR, 1.45; 95\% CI: $1.07-1.96)$.

\section{DISCUSSION}

In the current study, we found a relatively high prevalence of overweight or obese rural children and adolescents, especially among male participants. Overweight status was associated with race, sleep duration, and family income in boys and lack of breakfast in girls. Having overweight parents was a risk factor for being overweight or obese in children and adolescents of either sex.

The prevalence of being overweight or obese in this population was higher than that observed in previous studies conducted in Xian and Nanjing, which are in western and eastern China, respectively $(10,11)$. However, it is similar to the rates in many metropolises reported from the National Surveys on Chinese Students' Constitution and Health in 2000, although different criteria for being overweight or obese were used (6). The prevalence in northeast China was lower than that of some other countries such as the United States, South Korea, Saudi Arabia, and Greece (12-16), and higher as compared with others $(17,18)$. Regional and racial differences might contribute to these inconsistent results.

We found that the percentage of overweight and obese students was much higher among the males. Unlike the results from other countries (14,19-21), most studies in China, including the present study, found that in general, boys were more often obese than girls $(10,11,22-24)$. The male-specific prevalence might be related to gender differences in feeding, resulting from the higher value placed on a son in traditional Chinese culture. It also might be explained by discrepancies in body image between the two genders. Females are more concerned about their weight and body shape. Among males, a strong and big body in particular is considered healthy in northeast China.

Many epidemiological studies have indicated that short sleep duration is a risk factor of being overweight or obese among children and adolescents $(10,25-29)$. In a cross-sectional study of 8,274 children aged 6-7y, Sekine et al. found that the adjusted 
Table 2. Prevalence of overweight/obesity among children and adolescents in Liaoning Province, China

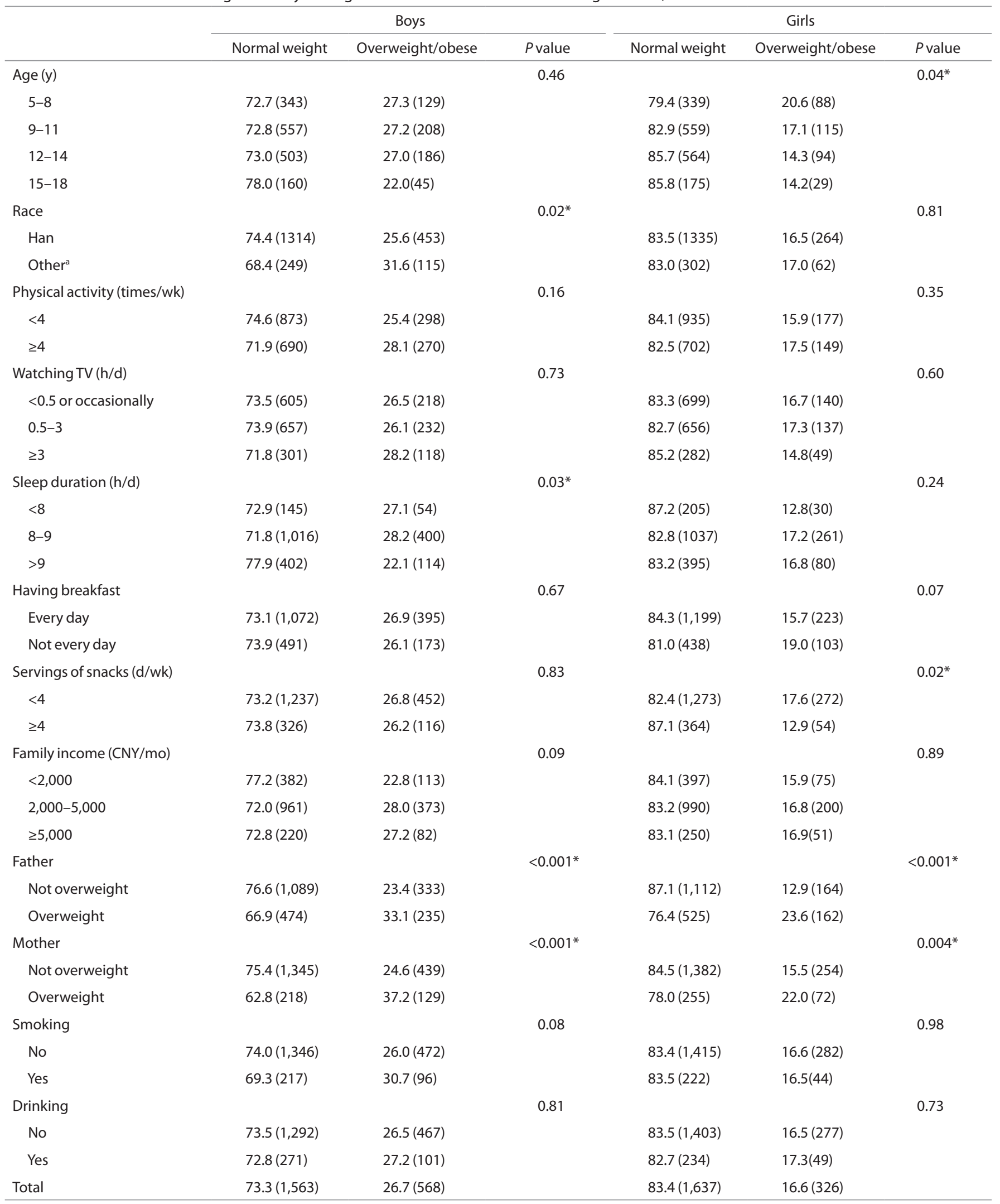

Data are expressed as $\%(n) .{ }^{*} P<0.05$, statistically significant difference. 


\section{Articles | Guo et al.}

Table 3. Multivariate analysis of risk factors associated with overweight/obesity by sex

\begin{tabular}{|c|c|c|c|c|c|c|}
\hline & \multicolumn{3}{|c|}{ Boys } & \multicolumn{3}{|c|}{ Girls } \\
\hline & OR & $95 \% \mathrm{Cl}$ & $P$ value & OR & $95 \% \mathrm{Cl}$ & $P$ value \\
\hline \multicolumn{7}{|l|}{ Age (y) } \\
\hline $9-11$ & 1.01 & $0.77-1.31$ & 0.96 & 0.78 & $0.57-1.07$ & 0.12 \\
\hline $12-14$ & 0.94 & $0.72-1.24$ & 0.67 & 0.66 & $0.47-0.93$ & $0.02^{*}$ \\
\hline \multicolumn{7}{|l|}{ Race } \\
\hline Han & 1.00 & & & 1.00 & & \\
\hline Other $^{\mathrm{a}}$ & 1.36 & $1.06-1.75$ & $0.02^{*}$ & 1.08 & $0.79-1.47$ & 0.63 \\
\hline \multicolumn{7}{|c|}{ Physical activity (times/wk) } \\
\hline$<4$ & 1.00 & & & 1.00 & & \\
\hline $0.5-3$ & 0.96 & $0.77-1.20$ & 0.73 & 1.03 & $0.79-1.34$ & 0.85 \\
\hline$\geq 3$ & 1.07 & $0.81-1.41$ & 0.65 & 0.91 & $0.63-1.32$ & 0.63 \\
\hline \multicolumn{7}{|l|}{ Sleep duration $(\mathrm{h} / \mathrm{d})$} \\
\hline$<8$ & 1.04 & $0.72-1.50$ & 0.83 & 0.79 & $0.50-1.25$ & 0.31 \\
\hline $8-9$ & 1.00 & & & 1.00 & & \\
\hline$>9$ & 0.72 & $0.57-0.92$ & $0.01^{*}$ & 0.97 & $0.72-1.29$ & 0.81 \\
\hline \multicolumn{7}{|l|}{ Having breakfast } \\
\hline Every day & 1.00 & & & 1.00 & & \\
\hline $2,000-5,000$ & 1.34 & $1.05-1.72$ & $0.02^{*}$ & 1.08 & $0.81-1.46$ & 0.60 \\
\hline$\geq 5,000$ & 1.27 & $0.91-1.77$ & 0.17 & 1.11 & $0.74-1.65$ & 0.62 \\
\hline \multicolumn{7}{|l|}{ Father } \\
\hline Not overweight & 1.00 & & & 1.00 & & \\
\hline Overweight & 1.54 & $1.26-1.89$ & $<0.001^{*}$ & 2.01 & $1.57-2.57$ & $<0.001^{*}$ \\
\hline \multicolumn{7}{|l|}{ Mother } \\
\hline Not overweight & 1.00 & & & 1.00 & & \\
\hline Overweight & 1.73 & $1.35-2.22$ & $<0.001^{*}$ & 1.45 & $1.07-1.96$ & $0.02^{*}$ \\
\hline \multicolumn{7}{|l|}{ Smoking } \\
\hline No & 1.00 & & & 1.00 & & \\
\hline Yes & 1.36 & $0.97-1.92$ & 0.08 & 1.14 & $0.73-1.75$ & 0.57 \\
\hline \multicolumn{7}{|l|}{ Drinking } \\
\hline No & 1.00 & & & 1.00 & & \\
\hline Yes & 0.88 & $0.63-1.22$ & 0.43 & 1.04 & $0.68-1.58$ & 0.86 \\
\hline
\end{tabular}

CNY, Chinese yuan (1 CNY = 0.163 USD); OR, odds ratio; USD, US dollar; $95 \%$ Cl, $95 \%$ confidence interval.

${ }^{*} P<0.05$ for the independent association between overweight/obesity and each factor after adjusting for the remaining factors.

Including some ethnic minorities in China, such as Mongol and Manchu. 
odds for obesity were $1.49,1.89$, and 2.87 for sleep durations of 9-10, $8-9$, and $<8 \mathrm{~h}$, respectively, as compared with children who slept for $\geq 10 \mathrm{~h}$ (26). High frequency of adequate sleep was inversely associated with obesity among Taiwan adolescents aged 13-18 y (27). In line with previous studies in China $(10,25)$, we found that a longer sleep duration was a protective factor against being overweight or obese. Underlying mechanisms responsible for this might include upregulation of appetite, alterations in glucose metabolism, and decreased energy expenditure $(30,31)$. However, in our study, this association was observed only among boys, which is contrary to some studies $(32,33)$ but in agreement with others $(26,28,29)$. We are unable to account for the sex-specific differences of our results, involving changes in physiology and body composition that accompany puberty, and differences in sleep patterns, although they have been formerly discussed $(28,32,33)$. The precise mechanism is still under debate and deserves further evaluation.

Skipping breakfast has been reported to be an important determinant of childhood and adolescent overweight and obesity (33). Breakfast consumption was associated with higher intakes of carbohydrate, dietary fiber, and certain micronutrients, as well as lower intake of fats (34). In a study of 35,000 Swedish students aged 13-16 y, skipping breakfast was related to overweight more than alcohol drinking and even more than physical inactivity (35). As compared with the girls who ate breakfast every day, in the current study, the risk of being overweight or obese was 1.5-fold higher for girls not having breakfast. This affirms the importance of the regular consumption of breakfast. However, relatively few studies in China have investigated this issue, especially in rural areas, indicating that it is an easily overlooked life habit, and more attention is needed.

The current study showed that having overweight parents was a strong independent risk factor for being overweight or obese. Similar findings have been reported from other parts of China $(10,36)$. Parents' genetic and behavior factors are transmitted to their children consciously or unconsciously. Parental choices have previously been shown to have a marked effect on the food selection of their children. It was reported that children with obese or overweight parents had a higher preference for fatty foods and a more "overeating-type" eating style (37). The essential role of parents in the prevention of pediatric overweight and obesity should never be overlooked. We found that the magnitude of the association between parental overweight and child overweight was larger for boys who had an overweight mother vs. an overweight father. For girls, the magnitude of the association was higher for those with an overweight father vs. an overweight mother. More studies are expected to investigate this phenomenon.

With regard to some lifestyle behaviors, such as physical inactivity and long hours of TV watching, we failed to find a significant relation to childhood and adolescent overweight or obesity. In contrast to some studies, some others also found negative associations between these factors and pediatric obesity, indicating that different populations might lead to various outcomes. Yi et al. (10) found that physical inactivity was not significantly associated with obesity in children aged 7-18 y from a city in north China. This was in line with the result from a study conducted among 1,869 adolescent school students in Saudi Arabia (14). In a cluster-randomized controlled trial, Reilly et al. (38) demonstrated that physical activity did not improve weight status after enhanced program and health education in young children. Although obesity and overweight were found to be associated with watching TV for more than $2 \mathrm{~h} / \mathrm{d}$ among schoolchildren in the north of Jordan (20), the relationship turned out to be negative in the study conducted in Saudi Arabia using the same cut points (14). Jabre et al. (39) also failed to detect a significant association between time spent in watching TV and overweight in children aged 6-8 y. Therefore, considering the different features of the populations and various definitions for the variables, the negative associations between these factors and pediatric obesity that we found in the current study were quite possible. In addition, insufficient sample size might also be a potential reason.

This study has some limitations. First, the data are not representative of children and adolescents throughout China. Second, some of the children and parents did not complete the questionnaire fully, resulting in vacancies for several variables. Therefore, the final sample size is smaller than the original. In addition, these analyses rely on self-reports from children and their parents, which might compromise accuracy. Moreover, our results are based on a cross-sectional design, and therefore, no cause-and-effect relationships could be established definitively.

\section{Conclusion}

In summary, the current study indicated that being overweight or obese is highly prevalent in children and adolescents in this northeast China population sample. Short sleep duration, skipping breakfast, and overweight parents were found to be risk factors. The risk profile in this population differed from that reported in other regions. To reduce the prevalence of childhood and adolescent obesity, it is of key importance to establish strategies that are specifically based on the risk factors, and sex should be taken into account when targeting children and adolescents in rural areas for health-promoting interventions.

\section{METHODS}

\section{Study Population}

We conducted a cross-sectional, school-based study from July 2010 to January 2011 in rural areas located $\sim 55 \mathrm{~km}$ northwest of the center of Shenyang, Liaoning Province, to assess the prevalence of overweight and obese rural Chinese children and adolescents and factors associated with these conditions. A total of 7,637 students aged 5-18 y were recruited, with an overall response rate of $89 \%$ (Figure 1). We adopted a multistage, stratified cluster-sampling scheme and included samples from the northern, southern, western, and eastern regions of rural Shenyang. Three public schools were selected randomly from each geographic region. Subjects from all the classes in each school were included. Overall, 12 public schools from these regions and 162 classes were selected. Participants who failed to fulfill the process or who provided incomplete data required for the study were excluded. Forty-four participants known to have chronic heart, renal, or hepatic disease were also excluded. The final sample consisted of 4,094 students, including 2,131 boys and 1,693 girls. The parents of all subjects provided informed consent. The study was approved by the Ethics Committee of China Medical University. 


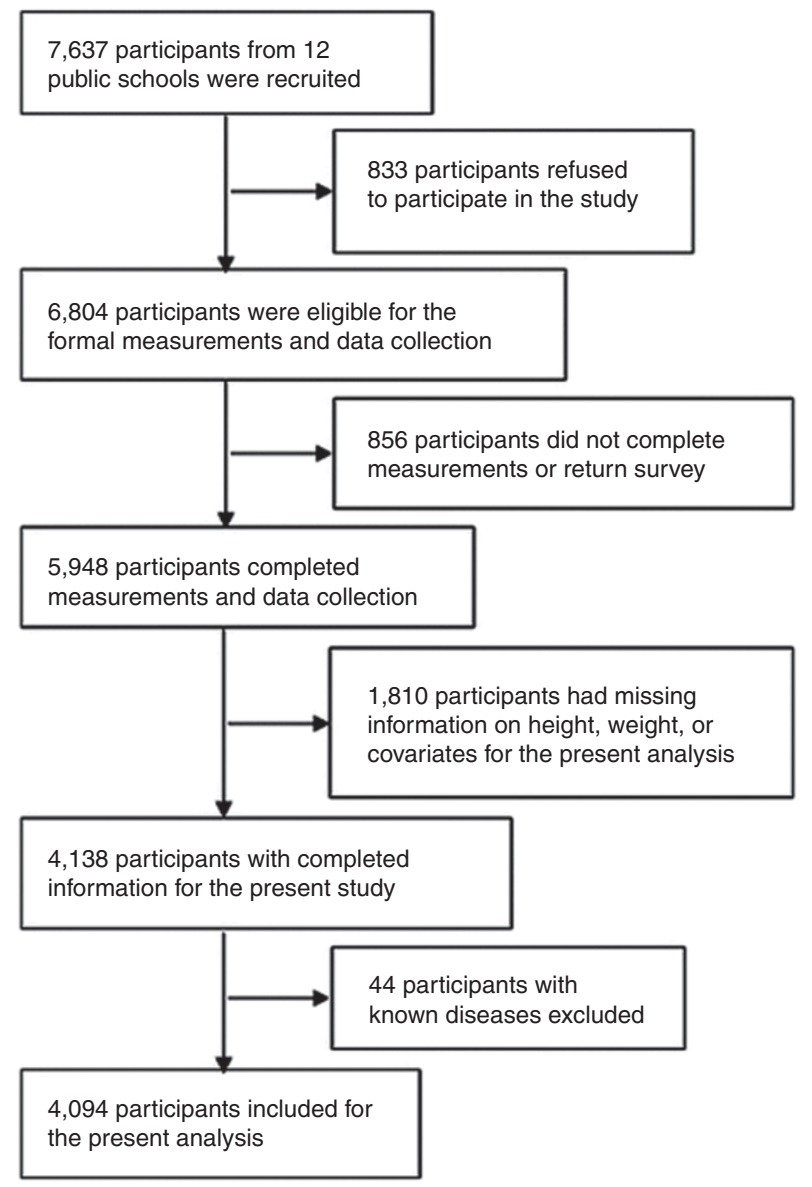

Figure 1. Flowchart of participant recruitment and derivation.

\section{Outcome Variable}

In accordance with the standardized technique described by the Fourth Report on the Diagnosis, Evaluation, and Treatment of High Blood Pressure in Children and Adolescents (40), blood pressure (BP) was measured after the subject had rested for at least $5 \mathrm{~min}$, using a mercury sphygmomanometer and appropriate-size cuff by welltrained personnel. The participants were advised to avoid coffee, tea, and exercise for at least $30 \mathrm{~min}$ before the measurement and remained seated with the arm supported at heart level during the measurement. The average of two measurements was used in the analysis. With the subjects wearing light clothes without shoes, body weight was measured to the nearest $100 \mathrm{~g}$ with a professional scale, and height was measured to the nearest $0.5 \mathrm{~cm}$ with a stadiometer. BMI was calculated as weight in kilograms divided by the squared height in meters.

BP status was defined according to the Fourth Report on the Diagnosis, Evaluation, and Treatment of High Blood Pressure in Children and Adolescents (40). Prehypertension was defined as systolic BP and/or diastolic BP (DBP) $\geq 90$ th and $<95$ th percentile, respectively, for age, sex, and height, or if the systolic BP was $\geq 120 \mathrm{~mm} \mathrm{Hg}$ or the DBP was $\geq 80 \mathrm{~mm} \mathrm{Hg}$. Hypertension was defined as systolic BP and/or DBP $\geq 95$ th percentile. Weight class was based on the tables of the International Obesity Task Force from data gathered from the United States, Brazil, the Netherlands, Hong Kong, the United Kingdom, and Singapore (41). Parental overweight was defined as $\mathrm{BMI} \geq 25$ using the criteria of the World Health Organization (42).

\section{Covariates}

Information concerning personal characteristics was collected by trained personnel (cardiologists, doctors of internal medicine, and pediatricians) using a questionnaire, and included age, sex, race, smoking and drinking status, frequency of physical activities per week, hours of watching television per day, sleep duration (including nocturnal sleep duration and nap duration), and family income. The younger children answered these questions with the help of their parents. Parents reported their own height and weight as well as family income. The frequency of having breakfast and snacks was recorded, with the possible responses "never or occasionally," "less than once a week," "1-3 days per week," "4-6 days per week," and "every day." Variables in the regression model included age (5-8/9-11/12-14/15$18 \mathrm{y})$, race (Han/others), physical activity $(<4 / \geq 4$ times per wk), watching TV $(<0.5$ or occasionally/0.5-3/ $\geq 3 \mathrm{~h}$ per $\mathrm{d})$, sleep duration $(<8 / 8-9 / \geq 9$ h per $\mathrm{d})$, having breakfast (every day/not every day), servings of snacks $(<4 / \geq 4 \mathrm{~d}$ per week), family income $(<2,000 / 2,000$ $5,000 / \geq 5,000 \mathrm{CNY}$ per month), smoking and drinking status (yes/ no), and weight status of parents (overweight/not overweight).

\section{Statistical Analysis}

Continuous variables are expressed as mean values and SD, and categorical variables are described as frequencies and percentages. Comparisons were performed using $t$ tests, $\chi^{2}$ tests, and one-way ANOVAs. The association between risk factors and being overweight or obese was tested using multivariable logistic regression models by sex, with ORs and 95\% CIs calculated. All the statistical analyses were performed using SPSS version 17.0 software (SPSS, Chicago, IL). $P<$ 0.05 was considered statistically significant.

\section{STATEMENT OF FINANCIAL SUPPORT}

No financial assistance was received to support this study.

Disclosure: The authors report no conflict of interest.

\section{REFERENCES}

1. Chan RS, Woo J. Prevention of overweight and obesity: how effective is the current public health approach. Int J Environ Res Public Health 2010;7:765-83.

2. Daniels SR. Complications of obesity in children and adolescents. Int J Obes 2009;33:Suppl 1:60-5.

3. Arens R, Muzumdar H. Childhood obesity and obstructive sleep apnea syndrome. J Appl Physiol 2010;108:436-44.

4. Weiss R, Dziura J, Burgert TS, et al. Obesity and the metabolic syndrome in children and adolescents. N Engl J Med 2004;350:2362-74.

5. Engeland A, Bjørge T, Tverdal A, Søgaard AJ. Obesity in adolescence and adulthood and the risk of adult mortality. Epidemiology 2004;15:79-85.

6. Ji CY, Sun JL, Chen TJ. [Dynamic analysis on the prevalence of obesity and overweight school-age children and adolescents in recent 15 years in China]. Zhonghua Liu Xing Bing Xue Za Zhi 2004;25:103-8.

7. Ma J, Cai CH, Wang HJ, et al. [The trend analysis of overweight and obesity in Chinese students during 1985 - 2010]. Zhonghua Yu Fang Yi Xue Za Zhi 2012;46:776-80.

8. Jiang JX, Xing GR, Wang HS, Ma Y, Gong LM, Xu L. [Family risk factors of overweight and obesity in preschool children]. Zhonghua Er Ke Za Zhi 2007;45:172-5.

9. Liu JM, Ye R, Li S, et al. Prevalence of overweight/obesity in Chinese children. Arch Med Res 2007;38:882-6.

10. Yi X, Yin C, Chang M, Xiao Y. Prevalence and risk factors of obesity among school-aged children in Xi'an, China. Eur J Pediatr 2012;171:389-94.

11. Xu F, Li J, Ware RS, Owen N. Associations of television viewing time with excess body weight among urban and rural high-school students in regional mainland China. Public Health Nutr 2008;11:891-6.

12. Thorpe LE, List DG, Marx T, May L, Helgerson SD, Frieden TR. Childhood obesity in New York City elementary school students. Am J Public Health 2004;94:1496-500.

13. Kim HM, Park J, Kim HS, Kim DH, Park SH. Obesity and cardiovascular risk factors in Korean children and adolescents aged 10-18 years from the Korean National Health and Nutrition Examination Survey, 1998 and 2001. Am J Epidemiol 2006;164:787-93.

14. Mahfouz AA, Shatoor AS, Khan MY, Daffalla AA, Mostafa OA, Hassanein MA. Nutrition, physical activity, and gender risks for adolescent obesity in Southwestern Saudi Arabia. Saudi J Gastroenterol 2011;17:318-22. 
15. Ferreira RJ, Marques-Vidal PM. Prevalence and determinants of obesity in children in public schools of Sintra, Portugal. Obesity (Silver Spring) 2008;16:497-500.

16. Cassimos D, Sidiropoulos H, Batzios S, Balodima V, Christoforidis A. Sociodemographic and dietary risk factors for excess weight in a greek pediatric population living in Kavala, Northern Greece. Nutr Clin Pract 2011;26:186-91.

17. Pirinçci E, Durmus B, Gündogdu C, Açik Y. Prevalence and risk factors of overweight and obesity among urban school children in Elazig city, Eastern Turkey, 2007. Ann Hum Biol 2010;37:44-56.

18. Hajian-Tilaki KO, Sajjadi P, Razavi A. Prevalence of overweight and obesity and associated risk factors in urban primary-school children in Babol, Islamic Republic of Iran. East Mediterr Health J 2011;17:109-14.

19. Sanigorski AM, Bell AC, Kremer PJ, Swinburn BA. High childhood obesity in an Australian population. Obesity (Silver Spring) 2007;15: 1908-12.

20. Khader Y, Irshaidat O, Khasawneh M, Amarin Z, Alomari M, Batieha A. Overweight and obesity among school children in Jordan: prevalence and associated factors. Matern Child Health J 2009;13:424-31.

21. Tuan NT, Butte NF, Wang Y. Demographic and socioeconomic correlates of adiposity assessed with dual-energy X-ray absorptiometry in US children and adolescents. Am J Clin Nutr 2012;96:1104-12.

22. Wang H, Ran YC, Cao L, Li W, Zhang J, Chen J. Epidemiological investigation of obesity in children and adolescents aged 0-18 years in Chengdu. Xian Dai Yu Fang Yi Xue 2008;35:460-2.

23. Cui Z, Huxley R, Wu Y, Dibley MJ. Temporal trends in overweight and obesity of children and adolescents from nine Provinces in China from 1991-2006. Int J Pediatr Obes 2010;5:365-74.

24. Zhang YX, Wang SR. Distribution of body mass index and the prevalence changes of overweight and obesity among adolescents in Shandong, China from 1985 to 2005. Ann Hum Biol 2008;35:547-55.

25. Shan XY, Xi B, Cheng H, Hou DQ, Wang Y, Mi J. Prevalence and behavioral risk factors of overweight and obesity among children aged 2-18 in Beijing, China. Int J Pediatr Obes 2010;5:383-9.

26. Sekine M, Yamagami T, Handa K, et al. A dose-response relationship between short sleeping hours and childhood obesity: results of the Toyama Birth Cohort Study. Child Care Health Dev 2002;28:163-70.

27. Chen MY, Wang EK, Jeng YJ. Adequate sleep among adolescents is positively associated with health status and health-related behaviors. BMC Public Health 2006;6:59.
28. Knutson KL. Sex differences in the association between sleep and body mass index in adolescents. J Pediatr 2005;147:830-4.

29. Chaput JP, Brunet M, Tremblay A. Relationship between short sleeping hours and childhood overweight/obesity: results from the 'Québec en Forme' Project. Int J Obes (Lond) 2006;30:1080-5.

30. Knutson KL. Sleep duration and cardiometabolic risk: a review of the epidemiologic evidence. Best Pract Res Clin Endocrinol Metab 2010;24:731-43.

31. Knutson KL, Spiegel K, Penev P, Van Cauter E. The metabolic consequences of sleep deprivation. Sleep Med Rev 2007;11:163-78.

32. Yu Y, Lu BS, Wang B, et al. Short sleep duration and adiposity in Chinese adolescents. Sleep 2007;30:1688-97.

33. Sun Y, Sekine M, Kagamimori S. Lifestyle and overweight among Japanese adolescents: the Toyama Birth Cohort Study. J Epidemiol 2009;19:303-10.

34. Ruxton $\mathrm{CH}$, Kirk TR. Breakfast: a review of associations with measures of dietary intake, physiology and biochemistry. Br J Nutr 1997;78:199-213.

35. Croezen S, Visscher TL, Ter Bogt NC, Veling ML, Haveman-Nies A. Skipping breakfast, alcohol consumption and physical inactivity as risk factors for overweight and obesity in adolescents: results of the E-MOVO project. Eur J Clin Nutr 2009;63:405-12.

36. Jingxiong J, Rosenqvist U, Huishan W, et al. Relationship of parental characteristics and feeding practices to overweight in infants and young children in Beijing, China. Public Health Nutr 2009;12:973-8.

37. Wardle J, Guthrie C, Sanderson S, Birch L, Plomin R. Food and activity preferences in children of lean and obese parents. Int J Obes Relat Metab Disord 2001;25:971-7.

38. Reilly JJ, Kelly L, Montgomery C, et al. Physical activity to prevent obesity in young children: cluster randomised controlled trial. BMJ 2006;333:1041.

39. Jabre P, Sikias P, Khater-Menassa B, Baddoura R, Awada H. Overweight children in Beirut: prevalence estimates and characteristics. Child Care Health Dev 2005;31:159-65.

40. National High Blood Pressure Education Program Working Group on High Blood Pressure in Children and Adolescents. The fourth report on the diagnosis, evaluation, and treatment of high blood pressure in children and adolescents. Pediatrics 2004;114:Suppl 2:555-76.

41. Cole TJ, Bellizzi MC, Flegal KM, Dietz WH. Establishing a standard definition for child overweight and obesity worldwide: international survey. BM] 2000;320:1240-3.

42. World Health Organization. Obesity: Preventing and Managing the Global Epidemic. Report of a WHO Consultation. World Health Organ Tech Rep Ser 2000;894:i-xii,1-253. 